\title{
Can Colony Size of Honeybees (Apis mellifera) Be Used as Predictor for Colony Losses Due to Varroa destructor during Winter?
}

\author{
Coby van Dooremalen ${ }^{1, *(D)}$ and Frank van Langevelde ${ }^{2,3}$ (iD \\ 1 Bees@wur, Wageningen University and Research Centre, Droevendaalsesteeg 1, \\ 6708 PB Wageningen, The Netherlands \\ 2 Wildlife Ecology and Conservation Group, Wageningen University and Research Centre, \\ Droevendaalsesteeg 3a, 6708 PB Wageningen, The Netherlands; frank.vanlangevelde@wur.nl \\ 3 School of Life Sciences, Westville Campus, University of KwaZulu-Natal, Durban 4000, South Africa \\ * Correspondence: coby.vandooremalen@wur.nl
}

Citation: van Dooremalen, C.; van Langevelde, F. Can Colony Size of Honeybees (Apis mellifera) Be Used as Predictor for Colony Losses Due to Varroa destructor during Winter? Agriculture 2021, 11, 529. https:// doi.org/10.3390/agriculture11060529

Academic Editors: Małgorzata Bieńkowska and Anna Gajda

Received: 13 May 2021

Accepted: 2 June 2021

Published: 7 June 2021

Publisher's Note: MDPI stays neutral with regard to jurisdictional claims in published maps and institutional affiliations.

Copyright: (c) 2021 by the authors. Licensee MDPI, Basel, Switzerland. This article is an open access article distributed under the terms and conditions of the Creative Commons Attribution (CC BY) license (https:// creativecommons.org/licenses/by/ $4.0 /)$.

\begin{abstract}
For more than three decades, honeybee colonies (Apis mellifera) have experienced high losses during winter and these losses are still continuing. It is crucial that beekeepers monitor their colonies closely and anticipate losses early enough to apply mitigating actions. We tested whether colony size can be used as early predictor for potential colony losses, in particular due to the parasitic mite Varroa destructor. $V$. destructor is one of the most important causes of these losses. Such an early predictor for potential $V$. destructor induced losses is especially relevant as measuring $V$. destructor load in colonies is difficult and cumbersome. Over three years, we monitored colonies with high and low $V$. destructor loads from July until March of the next year. We found that differences in colony size were only visible after November, even though we lost almost all colonies every winter in the group with a high $V$. destructor load. In the Northern hemisphere, November is considered to be too late for beekeepers to strengthen colonies in preparation for winter. We therefore argue that early warning signs for potential colony losses due to $V$. destructor are urgently needed to allow beekeepers to prevent winter losses. We discuss the role of precision apiculture in monitoring the health and productivity of beehive colonies.
\end{abstract}

Keywords: early warning; honeybee colony losses; beekeeping; parasitic mites; precision apiculture

\section{Introduction}

For more than three decades, honeybee colonies (Apis mellifera) have experienced high losses during winter, especially in the Northern hemisphere, and these losses are still continuing [1-3]. It is crucial that beekeepers can anticipate these losses early enough to apply mitigating actions. Therefore, methods for early warning of potential winter losses are urgently needed [4-6]. This early warning is useful when (1) winter losses can be predicted early enough for beekeepers to anticipate or intervene, and (2), the predictors can be measured relatively easy and quick. In this study, we tested whether colony size can be used as an early predictor for potential losses in honeybee colonies, as larger colonies show a larger survival chance [6,7]. We aimed, in particular, at colony size in relation to the parasitic mite Varroa destructor, as this mite is considered to be one of the most important causes for the current high winter losses of honeybees in the Northern hemisphere [8-12].

This is especially true for the temperate zone in the Northern hemisphere, early detection of potential winter losses means September the latest-well before bees enter the winter cluster and during winter preparation-as this is the last window of opportunity to strengthen or merge weak colonies before they enter the winter period [7]. Strengthening (i.e., adding bees from healthy colonies) or merging (i.e., combining two weak colonies) are expensive interventions as they imply pre-calculated losses of at least one colony, so 
that they are considered a last resort. Predictive markers can also be used to apply control treatments in time. Treatment can be done in such a way as to avoid blind chemical treatment, to prevent resistance development for these acaricides of the mites, and to reduce acaricide residues in honey and bee wax. Late summer is suggested to be the latest for treatment against $V$. destructor, also for merged colonies, to prevent negative effects on the long-lived winter bees [13-15].

Several studies tested the presence and loads of honeybee pathogens or colony health as predictive markers for winter honeybee colony losses $[4,5,16]$. V. destructor infestation levels in colonies are suggested to be used to anticipate winter losses [4-6]. However, the problem of using $V$. destructor infestation levels for early detection of potential losses is that infestation levels are low in the beginning of summer $[17,18]$, and although clinical symptoms are not visible and infestations often remain undetected at low to moderate infestation rates, the growth rate of the honeybee colony may be reduced [12]. Moreover, estimating $V$. destructor load in colonies in the field is difficult and cumbersome for beekeepers and scientists alike, especially when many colonies should be monitored over time $[5,19,20]$. Infection with deformed wing virus (DWV) and acute bee paralysis virus (ABPV) in October have also been suggested as predictors for winter losses [21,22], but that makes them rather late warning markers. Moreover, costs for beekeeping drastically increase when these types of markers have to be applied at large scale. Therefore, we question whether a simple and fast measure of colony size can be used to predict potential colony losses. This question is central in the development of precision apiculture [16]. When colony size can be used as early predictor, automatically monitoring hive weight may help beekeepers to prevent losses [23,24].

Some studies present incidental measurements over time of colony size in relation to $V$. destructor. For example, Delaplane and Hood [13] showed that colonies with high $V$. destructor infestation (in August) had more bees in December than colonies with low infestations, whereas Ostermann and Currie [25] showed that mite-inoculated colonies with high $V$. destructor infestation had smaller worker populations in August and September than controlled colonies. Only a few studies relate colony size to survival during or after winter [6]. Colonies that survived winter were larger in October than colonies that collapsed $[18,22]$. These two studies imply that colony size can be a predictive marker of colony losses during winter, but the differences in colony size between infested and uninfested colonies were detected relatively late in the season.

In this paper, we address two questions: (1) whether the decrease in colony size over time during the foraging season is related to $V$. destructor induced losses during winter, and (2), whether the effects of $V$. destructor on colony size can be found early enough in the season, namely before the winter preparation period. To answer the first question, we compared colony size during summer and survival during winter of colonies with high and low $V$. destructor loads. We did this by following colonies treated and untreated against $V$. destructor from July until March of the next year. It appeared that most colonies with high $V$. destructor loads did not survive until March next year, so we could also use this experiment to answer the second question.

\section{Materials and Methods}

\subsection{Experiment}

The fieldwork took place in the three years between July 2012 and March 2015 at an apiary in Wageningen, the Netherlands. For each year, new colonies $(n=20)$ were used. Colonies were kept in one-story, ten-frame wooden hives (inside measures Simplex) with a standard number of bees at the start of each year (4 frames of bees in 2012, and 6 frames in 2013 and 2014). Swarming was prevented during the experiment in all colonies. All colonies had continuous access to sugar dough (Apifonda).

For each year, the colonies in the group $(n=10)$ with a low infestation of $V$. destructor ( $\mathrm{V}$ - colonies) were treated in May/June with oxalic acid spray (30 g oxalic acid dihydrate in $1 \mathrm{~L}$ water). At that time, all colonies consisted of bees and open brood only (no capped 
brood cells). In August, the V- colonies were treated for 6 weeks with Apistan (2 strips per colony). The colonies in the group $(n=10)$ with a high infestation of $V$. destructor (V+ colonies) were neither treated in May/June nor in August. There were no signs that oxalic acids or Apistan resulted in significant bee death either during or directly after application [6].

\subsection{Data Collection}

Colony size was estimated by the percentage cover of the topside of the hive in the first week of each month - when weather permitted (see [6] for the justification of this method). The topside of the hive is what beekeepers see when they open their hive and it is the easiest, least invasive and fastest way to obtain data on colony size, e.g., compared to the more commonly used methods of estimating the number of bees on the different frames or weighing only the bees [26]. A puff of smoke was blown into the hive from below. After a minute, the lid was removed and a photo was taken from the topside. The percentage cover (standardized to one brood box) was calculated based on the number of pixels in the photo, namely the number of pixels of the area covered with bees on top and visible between the frames, divided by the topside of the inner volume of the hive. We used a standard size brood boxes (hives) with 10 frames (Simplex measures). For a comparative insight, this type of brood box, when fully occupied with bees ( $100 \%$ top coverage), contains approximately 17,000 [26]. In the first week of March of the next year, a final check-up of the colonies was performed to determine whether the colony was dead (no living bees and/or queen) or still alive.

The number of phoretic mites was monitored by monthly sampling of 100-200 bees between July and December and counting the number of mites. The worker bees were collected by scraping them off the rim of the brood nest and stored at $-20^{\circ} \mathrm{C}$ until counting. Distributions of age classes are assumed to be similar throughout the brood nest [27]. Collection of drones or the queen was avoided, but if it occurred, was not included in the analysis.

All bees in the samples were checked for the number of mites present using a stereomicroscope. Optimally, one would sample at least 300 bees to analyze $V$. destructor population dynamics throughout the whole season with frequent and destructive sampling of bees from healthy colonies ( $>10,000$ bees) [20]. In our study however, half of the colonies were not healthy and in general our colonies were small $(<7000$ bees at the start in 2012, estimated based on the assumption that $10 \%$ top cover equals 1 frame of bees, and one frame counts for approximately 1700 bees, as estimated by [26]. We felt that monthly sampling of 300 bees would reduce the colony size significantly and would therefore interfere with our colony size measurements. We collected per colony per month approximately $12.5 \mathrm{~g}$ of bees ( 100 bees) in 2012, $20 \mathrm{~g}$ of bees ( 160 bees) in 2013, and $15 \mathrm{~g}$ of bees ( 120 bees) in 2014. In 2012, we weighed 20 individual bees per colony, resulting in an average body mass of $124.7 \pm 1.6$ (sd) mg per bee and eight individuals per gram of bees.

To test the reliability of our sampling method we compared the standard error as a percentage of the mean between our dataset based on 100-200 bees per colony and the dataset as presented at Table 1 in [19] based on 300 bees per colony. The standard error was used (instead of the standard deviation) to correct for the difference in the number of colonies sampled between the datasets ( 10 colonies per group in our dataset, against $30.8 \pm 5.7$ (sd) colonies per group in [19]). In our dataset, the standard error was $18.6 \%$ of the mean in 2012 (100 bees), 15.7\% of the mean in 2013 ( 160 bees) and $18.9 \%$ of the mean in 2014 (120 bees), and very similar to the proportion as calculated from [19], which was $18.5 \%$. We therefore argue that our sampling of 100-200 bees per colony per month was sufficiently reliable to be used to separate low and high $V$. destructor loads.

\subsection{Statistics}

General mixed linear models were used to test the dependent variables; the number of mites per gram of bees (Ln-transformed +0.01 ) and the colony size, as a function of the 
acaricide treatment (fixed factor) or survival in March (fixed factor), year, and sampling month (repeated, colony as subject). The model with the lowest AIC in relation to the covariance structure was used.

The use of the percentage cover of the topside of the hive to estimate colony size is sensitive to differences in ambient temperature. To draw any conclusions about using colony size as a reliable predictive marker for winter loss, one should compare the sizes of the colonies under similar temperature conditions. Therefore we tested the relationship between colony size (Ln-transformed) and average daily temperature (Ln-transformed). We used a linear mixed model with year as the fixed factor and average daily temperature as the covariate.

In all models, Sidak post hoc tests for pair wise comparison were used to test for differences between groups within each month. Assumptions for normality were met in all tests. Unless explained differently, means are presented together with their standard error.

\section{Results}

Most of the $\mathrm{V}+$ colonies that were not treated against $V$. destructor died during the winter, whereas all V- colonies survived until March of the next year (Table 1). The number of mites per gram of bees was lower in 2012 compared to the years 2013 and 2014 (which were the same), but in all years the number of mites per gram bees in $\mathrm{V}+$ colonies increased towards the end of the year (Table 2, Figure 1). From September onwards, V+ colonies showed higher infestation levels compared to $\mathrm{V}$ - colonies. We noticed that many of the colonies not treated with acaricides did not show any infestation in July or August (Table 3).

Table 1. Colony survival in March, since the start of experiment in July the year before for colonies without acaricide treatment $(\mathrm{V}+)$ or with acaricide treatment $(\mathrm{V}-)$. Colony ${ }^{\#}$ indicates the number of starting colonies.

\begin{tabular}{ccccc}
\hline & \multicolumn{2}{c}{ V+ } & \multicolumn{2}{c}{ V- } \\
\hline Year & Colony $^{\#}$ & Survival & Colony $^{\#}$ & Survival \\
\hline 2012 & 10 & 0 & 8 & 8 \\
\hline 2013 & 10 & 2 & 10 & 10 \\
\hline 2014 & 10 & 3 & 10 & 10 \\
\hline
\end{tabular}

Colony size differed per year, month, and V. destructor infestation (Table 2, Figure 2). However, differences in colony size due to $V$. destructor infestation did not in general appear before December (Sidak post hoc test Varroa $\times$ Month). In one year (2014) differences due to $V$. destructor levels appeared a little earlier in the year, in November (Figure 2c). Differences in colony size based on survival (dead/alive in March) also did not appear during summer (Table 2, Figure 2). In October, the earliest difference in size was observed between the colonies that did not survive until March and the ones that did (2014, Figure 2f).

In 2012, we started with 25\% smaller colonies compared to 2013 and 2014 (which were the same). Colony sizes were largest during summer and smallest in winter. This general pattern of colony size over the experimental months was positively related to the average daily ambient temperature in the same months $\left(\mathrm{Year}_{2,19}=0.3, p=0.72\right.$; Average daily temperature per month $\mathrm{F}_{1,19}=41.0, p<0.001$; interaction $\mathrm{F}_{2,19}=0.7, p=0.50$; both Ln-transformed; Figure 3). The lack of an interactive effect between month and temperature on the colony size in our analysis justifies comparing colony size under similar temperature conditions, which allows us to draw the conclusion about the use of colony size. 


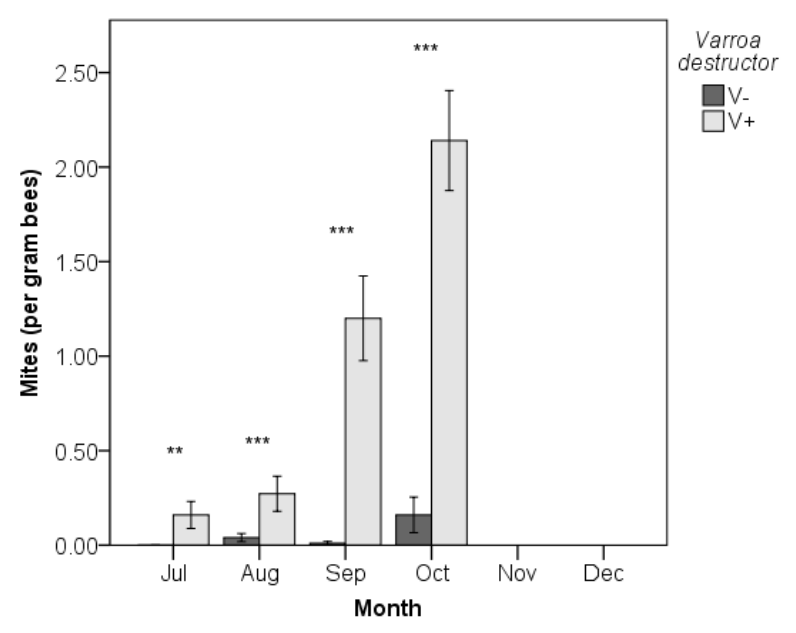

(a)

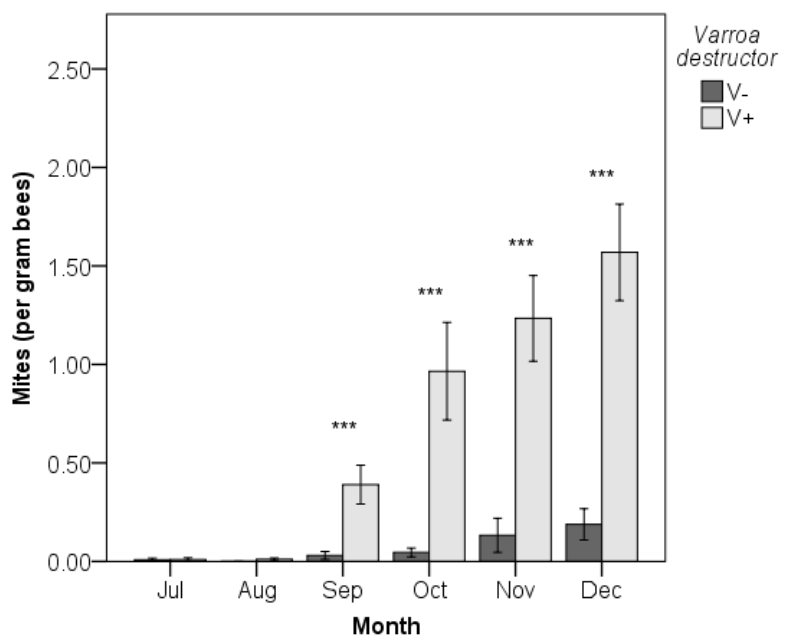

(b)

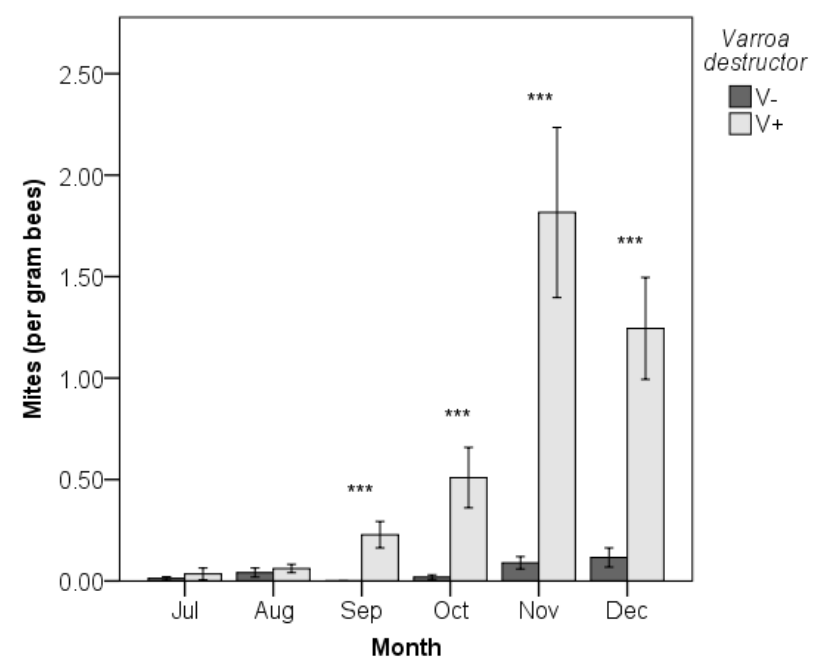

(c)

Figure 1. Number of $V$. destructor mites per gram of bees per month in 2012 (a), 2013 (b) and 2014 (c) for colonies without acaricide treatment $(\mathrm{V}+$, dark grey bars) or with acaricide treatment $(\mathrm{V}-$, light grey bars). Asterisks show differences between $\mathrm{V}-$ and $\mathrm{V}+\left({ }^{*} p<0.05\right.$; ${ }^{* *} p<0.01$; $\left.{ }^{* * *} p<0.001\right)$, where the data for the statistical test were Ln-transformed (+0.0005). 
Table 2. Results of the linear mixed models for the effects of Varroa destructor (Varroa). Year and month are shown, including their interaction with the number of mites per gram of bees and the colony size (\% top cover). For each factor in the model, the F- and $p$-values are given. For each model, we give the applied method of estimation (REML = restricted maximum likelihood), whether we Ln-transformed the dependent variable (Ln), the sample size $(n)$, the value of the Aikaike's information criterion (AIC) and the Repeated Covariance Type.

\begin{tabular}{|c|c|c|c|c|}
\hline Independent Variables & Stat. & Number of Mites & Colony Size (Varroa) & Colony Size (Survival) \\
\hline \multirow{2}{*}{ Year } & $\mathrm{F}$ & 11.5 & 69.2 & 70.3 \\
\hline & $p$ & $<0.001$ & $<0.001$ & $<0.001$ \\
\hline \multirow{2}{*}{ Month } & $\mathrm{F}$ & 68.8 & 167.0 & 157.4 \\
\hline & $p$ & $<0.001$ & $<0.001$ & $<0.001$ \\
\hline \multirow{2}{*}{ Varroa } & $\mathrm{F}$ & 197.1 & 36.6 & - \\
\hline & $p$ & $<0.001$ & $<0.001$ & - \\
\hline \multirow{2}{*}{ Survival } & $\mathrm{F}$ & - & - & 47.3 \\
\hline & $p$ & - & - & $<0.001$ \\
\hline \multirow{2}{*}{ Year $\times$ Month } & $\mathrm{F}$ & 2.5 & 18.4 & 13.2 \\
\hline & $p$ & 0.01 & $<0.001$ & $<0.001$ \\
\hline \multirow{2}{*}{ Year $\times$ Varroa } & $\mathrm{F}$ & 5.1 & 1.6 & - \\
\hline & $p$ & 0.01 & 0.21 & - \\
\hline \multirow{2}{*}{ Year $\times$ Survival } & $\mathrm{F}$ & - & - & 2.0 \\
\hline & $p$ & - & - & 0.14 \\
\hline \multirow{2}{*}{ Month $\times$ Varroa } & $\mathrm{F}$ & 20.6 & 16.6 & - \\
\hline & $p$ & $<0.001$ & $<0.001$ & - \\
\hline \multirow{2}{*}{ Month $\times$ Survival } & $\mathrm{F}$ & - & - & 19.4 \\
\hline & $p$ & - & - & $<0.001$ \\
\hline \multirow{2}{*}{ Year x Month $\times$ Varroa } & $\mathrm{F}$ & 0.51 & 3.4 & - \\
\hline & $p$ & 0.84 & $<0.001$ & - \\
\hline \multirow{2}{*}{ Year $x$ Month $\times$ Survival } & $\mathrm{F}$ & - & - & 4.5 \\
\hline & $p$ & - & - & $<0.001$ \\
\hline \multicolumn{2}{|c|}{ Estimation method } & REML & REML & REML \\
\hline \multicolumn{2}{|c|}{$\begin{array}{l}\text { Transformation } \\
n\end{array}$} & $\operatorname{Ln}(+0.01)$ & - & - \\
\hline \multicolumn{2}{|c|}{$n$} & 312 & 486 & 486 \\
\hline \multicolumn{2}{|l|}{ AIC } & 930.5 & 3442.3 & 3423.1 \\
\hline \multicolumn{2}{|c|}{ Repeated Covariance Type } & Compound symmetry & Unstructured & Unstructured \\
\hline
\end{tabular}

Table 3. Percentage of samples with no mites in the group of colonies not treated with acaricides $(\mathrm{V}+)$ for the different years and months.

\begin{tabular}{cccc}
\hline & & Year & $\mathbf{2 0 1 4}$ \\
\hline Month & $\mathbf{2 0 1 2}$ & $\mathbf{2 0 1 3}$ & 80 \\
\hline July & 40 & 90 & 40 \\
\hline August & 20 & 80 & 10 \\
\hline September & 0 & 10 & 10 \\
\hline October & 0 & 0 & 0 \\
\hline November & 0 & 0 & 0 \\
\hline December & 0 & 0 &
\end{tabular}




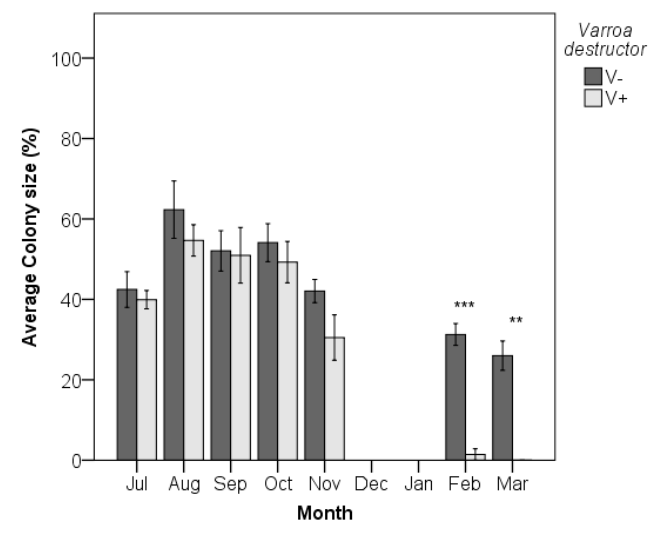

(a)

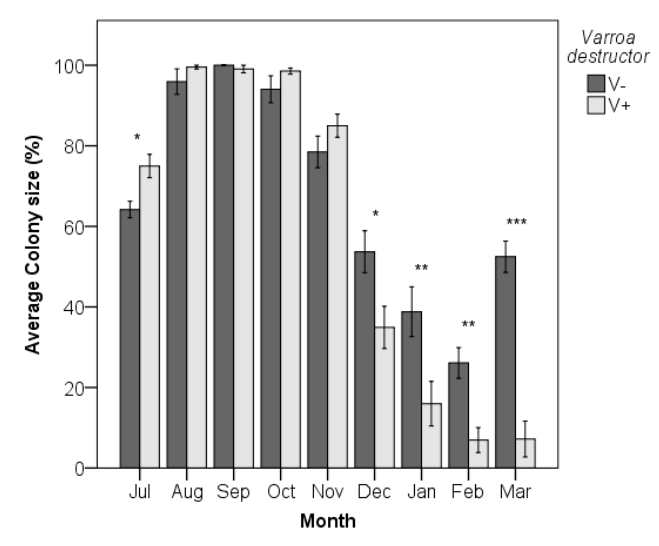

(b)

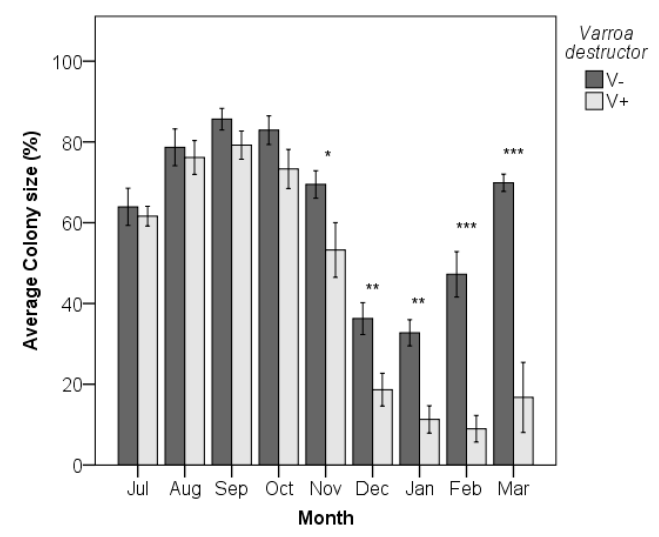

(c)

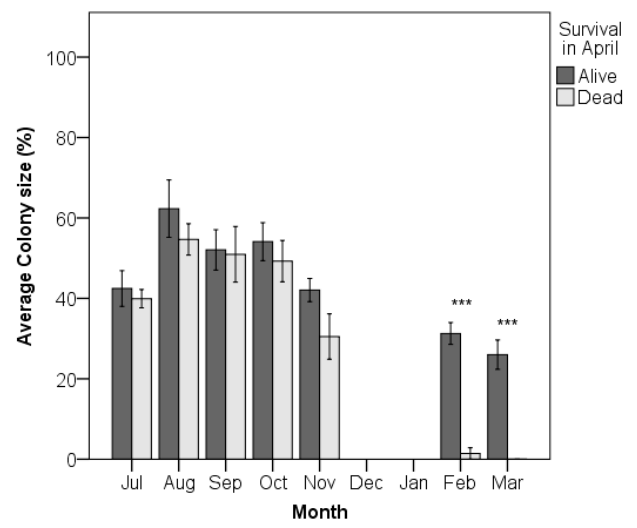

(d)

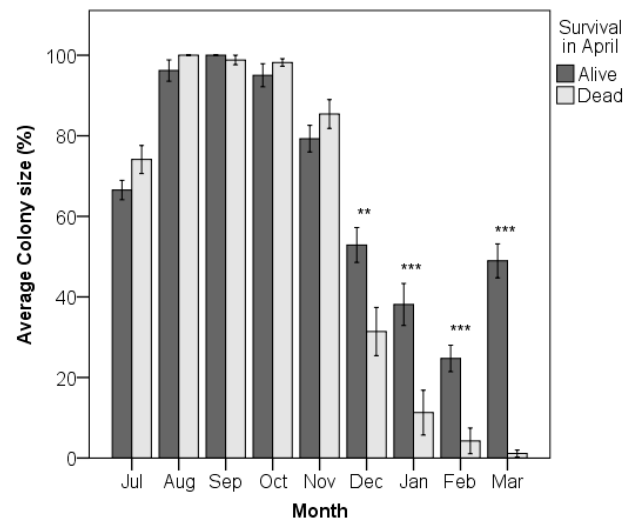

(e)

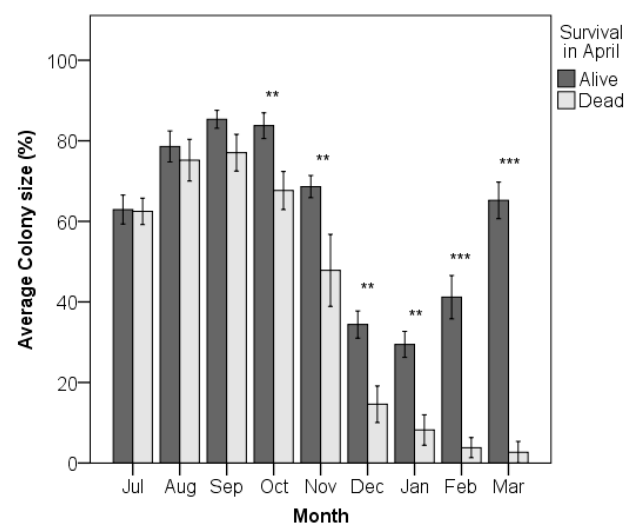

(f)

Figure 2. Average colony size (\%, [6]) per month for 2012 (a,d), 2013 (b,e), and 2014 (c,f) for colonies with (V-, dark grey bars) or without $(\mathrm{V}+$, light grey bars) acaricide treatment $(\mathbf{a}-\mathbf{c})$ or colonies alive (dark grey bars) or dead (light grey bars) in March (e-f). Asterisks show differences between series $\left({ }^{*} p<0.05 ;{ }^{* *} p<0.01 ;{ }^{* * *} p<0.001\right)$. 


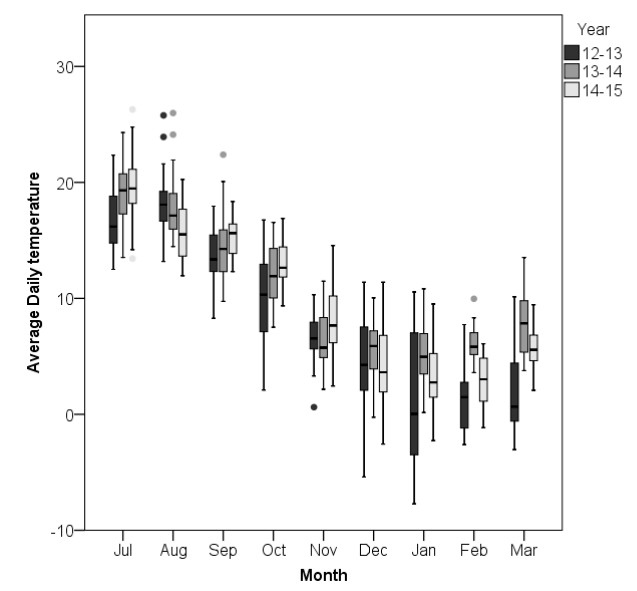

(a)

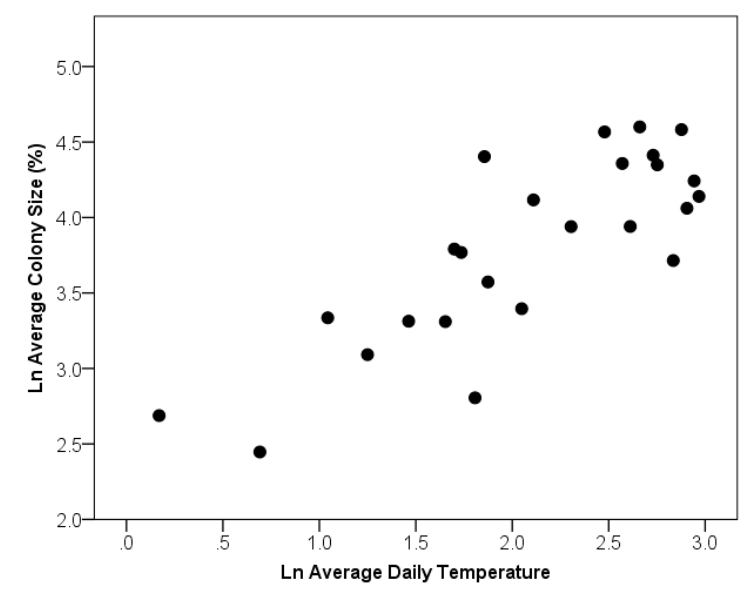

(b)

Figure 3. Average daily temperature $\left({ }^{\circ} \mathrm{C}\right.$ ) per month for 2012, 2013, and 2014 (a) and its relationship with the average colony size per month (\%) (b). In panel (b), the Ln-transformed data are shown.

\section{Discussion}

In this paper, we investigated whether colony size can be used as early warning predictor for colony losses during winter caused by the parasitic mite V. destructor. In our experiment covering three years, we found that the colonies with high loads of $V$. destructor had a much higher probability of mortality before next spring than the colonies with low loads. The differences in colony size between the colonies with low and high loads of $V$. destructor were only visible after November, even in years when differences in mite levels already occurred in July. Mere visual inspections of the colony sizes will therefore be insufficient as a predictive marker to prevent winter losses; late autumn is considered to be too late for beekeepers to strengthen colonies in preparation of winter. We acknowledge that due to different climatic conditions, the honeybee season can end earlier or later in different regions, but these differences do not alter our conclusion that differences in colony size are detectable only late in the season and hence cannot be used as an early warning for winter losses. Previous studies looking at differences in colony size as a result of $V$. destructor support our findings that differences in colony size are visible too late, although these studies did not investigate a time series of colony sizes as we did: smaller sizes in colonies with high $V$. destructor loads (than control colonies) in August and September [25], in October [18,22] and in December [13] have been reported.

The lack of differences in colony size during summer can be explained by a larger effect of $V$. destructor on the condition and life span of individual bees than on the number of bees in the colony per se $[6,12,15,28,29]$. No effect was found of different levels of $V$. destructor infestation on the number of brood cells in colonies [15], i.e., the future work force. Regardless of the absence of an early effect of $V$. destructor on colony size, we cannot reject the hypothesis that colony size may still be a valid marker to early predict colony losses in response to other stressors-especially those which (in)directly impact the number of bees in the colony [30], such as pesticides (modelling study in [31]).

In our study, infestation levels already showed differences between groups from July (2012) or September (2013 and 2014), but the numbers of (phoretic) V. destructor mites in these months were very low and many colonies in the untreated group (V+) showed no mites yet (40-90\% of the colonies in July, $20-80 \%$ of the colonies in August). We assume that most of the mites will be reproducing in the brood cells during this period and only very small numbers will be in the phoretic phase $[12,15,20]$. Due to the large variation in infestation levels and mite population growth patterns between years and the low phoretic mite levels during summer, our study indicates that the infestation level is also not very useful as a reliable predictive marker in an easy, quick and strait forward way during 
summer. Similar drawbacks are expected for other mite-related parameters such as visual inspection and counting the number of DWV symptoms.

The devastating effect of $V$. destructor infestation on colony survival is well known. Fries et al. [32] and Rosenkranz et al. [12] found that untreated colonies with an infestation rate exceeding $30 \%$ in adult bees during summer did not survive the following winter. Additionally, levels above $6 \%$ showed more than $10 \%$ losses [12,22]. In our study, we found lower thresholds: a mite infestation on adult bees ( $\mathrm{V}+$ group) in September as low as 3\% resulted in 70\% loss (2014), 5\% resulted in 80\% loss (2013), while $15 \%$ resulted in $100 \%$ loss (2012) of colonies during the winter. Interestingly, even with such high losses during winter among the colonies with the highest mite infestation, no difference in colony size was observed during summer and autumn. This means that beekeepers who are able to partly reduce mite infestation will be even less likely to find visual differences in colony size, but probably still have high chances of winter losses.

There is clearly a need to search for colony traits as predictive markers, rather than traits of individual bees (e.g., pathogen loads; [4,5], because measuring individual traits such as pathogen load in the field is time- and money-consuming, especially when beekeepers have many colonies that should be monitored over time. The way to develop such methods is to test the relative and interactive effects of multiple stressors in experiments on winter survival of colonies, following colony traits that indicate the functioning and condition of colonies from spring until the next spring [6]. Braga et al. [16] developed a classification algorithm based on a supervised machine learning approach to estimate the health status of colonies and to indicate an imminent collapsing state to beekeepers. Their promising results suggest a high precision classification model, which can be useful to self-predict healthy, unhealthy, and collapsing bee colony health states. This method and others in precision apiculture $[33,34]$ provide promising, non-invasive ways to measure colony health. Validation of simple and inexpensive methods of measuring colony traits is important for its acceptance and practical application. Experiments to test the potential of colony traits for early prediction of winter losses to feed these approached are still needed, including the development of devices or tools that allow easy and quick measurements of these colony traits.

Author Contributions: C.v.D. and F.v.L. conceived the idea, collected the data, analyzed the data and wrote the manuscript together. All authors have read and agreed to the published version of the manuscript.

Funding: The project was funded by the Ministry of Agriculture, Nature Conservation and Food Quality (LNV) of the Netherlands (BO-06-012) and by the European Union (National Honey Program NL08/2.1), year 2012/2013.

Institutional Review Board Statement: Not applicable.

Informed Consent Statement: Not applicable.

Data Availability Statement: Data are available upon reasonable request from the authors.

Conflicts of Interest: The authors declare no conflict of interest.

\section{References}

1. Van Engelsdorp, D.; Meixner, M.D. A historical review of managed honey bee populations in Europe and the United States and the factors that may affect them. J. Invertebr. Pathol. 2010, 103, 80-95. [CrossRef]

2. Ryabov, E.V.; Childers, A.K.; Chen, Y.; Madella, S.; Nessa, A.; van Engelsdorp, D.; Evans, J.D. Recent spread of Varroa destructor virus-1, a honey bee pathogen, in the United States. Sci. Rep. 2017, 7, 17447. [CrossRef]

3. Thoms, C.A.; Nelson, K.C.; Kubas, A.; Steinhauer, N.; Wilson, M.E. Beekeeper stewardship, colony loss, and Varroa destructor management. Ambio 2019, 48, 1209-1218. [CrossRef]

4. Dainat, B.; Evans, J.D.; Chen, Y.P.; Gauthier, L.; Neumann, P. Predictive markers of honey bee colony collapse. PLoS ONE 2012, 7, e32151. [CrossRef] [PubMed]

5. Francis, R.M.; Nielsen, S.L.; Kryger, P. Varroa-virus interaction in collapsing honey bee colonies. PLoS ONE 2013, 8, e57540. [CrossRef] [PubMed] 
6. Van Dooremalen, C.; Cornelissen, B.; Poleij-Hok-Ahin, C.; Blacquière, T. Single and interactive effects of Varroa destructor, Nosema spp., and imidacloprid on honey bee colonies (Apis mellifera). Ecosphere 2018, 9, e02378. [CrossRef]

7. Döke, M.A.; Frazier, M.; Grozinger, C.M. Overwintering honey bees: Biology and management. Curr. Opin. Insect Sci. 2015, 10, 185-193. [CrossRef]

8. Aizen, M.A.; Harder, L.D. The global stock of domesticated honey bees is growing slower than agricultural demand for pollination. Curr. Biol. 2009, 19, 915-918. [CrossRef]

9. Ellis, J.D.; Evans, J.D.; Pettis, J. Colony losses, managed colony population decline and Colony Collapse Disorder in the United States. J. Apic. Res. 2010, 49, 134-136. [CrossRef]

10. Le Conte, Y.; Ellis, M.; Ritter, W. Varroa mites and honey bee health: Can Varroa explain part of the colony losses? Apidologie 2010, 41, 353-363. [CrossRef]

11. Potts, S.G.; Biesmeijer, J.C.; Kremen, C.; Neumann, P.; Schweiger, O.; Kunin, W.E. Global pollinator declines: Trends, impacts and drivers. Trends Ecol. Evol. 2010, 25, 345-353. [CrossRef]

12. Rosenkranz, P.; Aumeier, P.; Ziegelmann, B. Biology and control of Varroa destructor. J. Invert. Pathol. 2010, 103, 96-119. [CrossRef]

13. Delaplane, K.S.; Hood, W.M. Effects of delayed acaricide treatment in honey bee colonies parasitized by Varroa jacobsoni and a late-season treatment threshold for the southeastern USA. J. Apic. Res. 1997, 36, 125-132. [CrossRef]

14. Currie, R.W.; Gatien, P. Timing acaricide treatments to prevent Varroa destructor (Acari: Varroidae) from causing economic damage to honey bee colonies. Can. Entomol. 2006, 13l8, 238-252. [CrossRef]

15. Van Dooremalen, C.; Gerritsen, L.; Cornelissen, B.; van der Steen, J.J.M.; van Langevelde, F.; Blacquière, T. Winter survival of individual honey bees and honey bee colonies depends on level of Varroa destructor infestation. PLoS ONE 2012, 7, e36285. [CrossRef]

16. Braga, A.R.; Gomes, D.G.; Rogers, R.; Hassler, E.E.; Freitas, B.M.; Cazier, J.A. A method for mining combined data from in-hive sensors, weather and apiary inspections to forecast the health status of honey bee colonies. Comput. Electron. Agric. 2020, 169, 105161. [CrossRef]

17. Sumpter, D.J.T.; Martin, S.J. The dynamics of virus epidemics in varroa-infested honey bee colonies. J. Anim. Ecol. 2004, 73, 51-63. [CrossRef]

18. Dainat, B.; Evans, J.D.; Chen, Y.P.; Gauthier, L.; Neumann, P. Dead or alive: Deformed wing virus and Varroa destructor reduce the life span of winter honeybees. Appl. Environ. Microbiol. 2012, 78, 981-987. [CrossRef]

19. Lee, K.V.; Moon, R.D.; Burkness, E.C.; Hutchison, W.D.; Spivak, M. Practical sampling plans for Varroa destructor (Acari: Varroidae) in Apis mellifera (Hymenoptera: Apidae) colonies and apiaries. J. Econ. Entomol. 2010, 103, 1039-1050. [CrossRef]

20. Dietemann, V.; Nazzi, F.; Martin, S.J.; Anderson, D.L.; BLocke, B.; Delaplane, K.S.; Wauquiez, Q.; Tannahill, C.; Frey, E.; Ziegelmann, B.; et al. Standard methods for varroa research. J. Apic. Res. 2013, 52, 1-54. [CrossRef]

21. Johnson, R.M.; Evans, J.D.; Robinson, G.E.; Berenbaum, M.R. Changes in transcript abundance relating to colony collapse disorder in honey bees (Apis mellifera). Proc. Nat. Ac. Sci. USA 2009, 106, 14790-14795. [CrossRef]

22. Genersch, E.; von der Ohe, W.; Kaatz, H.; Schroeder, A.; Otten, C.; Buchler, C.R.; Berg, S.; Ritter, W.; Muhlen, W.; Gisder, S.; et al. The German bee monitoring project: A long term study to understand periodically high winter losses of honey bee colonies. Apidologie 2010, 41, 332-352. [CrossRef]

23. Meikle, W.G.; Holst, N. Application of continuous monitoring of honeybee colonies. Apidologie 2015, 46, 10-22. [CrossRef]

24. Meikle, W.G.; Holst, N.; Colin, T.; Weiss, M.; Carroll, M.J.; McFrederick, Q.S.; Barron, A.B. Using within-day hive weight changes to measure environmental effects on honey bee colonies. PLoS ONE 2018, 13, e0197589. [CrossRef]

25. Ostermann, D.J.; Currie, R.W. Effect of formic acid formulations on honey bee (hymenoptera: Apidae) colonies and influence of colony and ambient conditions on formic acid concentration in the hive. J. Econ. Entomol. 2004, 97, 1500-1508. [CrossRef]

26. Delaplane, K.S.; van der Steen, J.; Guzman-Novoa, E. Standard methods for estimating strength parameters of Apis mellifera colonies. J. Apic. Res. 2013, 52, 1-12. [CrossRef]

27. Van der Steen, J.J.M.; Cornelissen, B.; Donders, J.; Blacquière, T.; van Dooremalen, C. How honey bees of successive age classes are distributed over a one storey, ten frames hive. J. Apicult. Res. 2012, 51, 174-178. [CrossRef]

28. Van Dooremalen, C.; Stam, E.; Gerritsen, L.; Cornelissen, B.; van der Steen, J.; van Langevelde, F.; Blacquière, T. Interactive effect of reduced pollen availability and Varroa destructor infestation limits growth and protein content of young honey bees. J. Insect. Physiol. 2013, 59, 487-493. [CrossRef]

29. Blanken, L.J.; van Langevelde, F.; van Dooremalen, C. Interaction between Varroa destructor and imidacloprid reduces flight capacity of honeybees. Proc. R. Soc. B Biol. Sci. 2015, 282, 20151738. [CrossRef]

30. Perry, C.J.; Søvik, E.; Myerscough, M.R.; Barron, A.B. Rapid behavioral maturation accelerates failure of stressed honey bee colonies. Proc. Nat. Acad. Sci. USA 2015, 112, 3427-3432. [CrossRef]

31. Henry, M.; Beguin, M.; Requier, F.; Rollin, O.; Odoux, J.F.; Aupinel, P.; Aptel, J.; Tchamitchian, S.; Decourtye, A. A common pesticide decreases foraging success and survival in honey bees. Science 2012, 336, 348-350. [CrossRef] [PubMed]

32. Fries, I.; Hansen, H.; Imdorf, A.; Rosenkranz, P. Swarming in honey bees (Apis mellifera) and Varroa destructor population development in Sweden. Apidologie 2003, 34, 389-398. [CrossRef] 
33. Catania, P.; Vallone, M. Application of a precision apiculture system to monitor honey daily production. Sensors 2020, $20,2012$. [CrossRef]

34. Henry, E.; Adamchuk, V.; Stanhope, T.; Buddle, C.; Rindlaub, N. Precision apiculture: Development of a wireless sensor network for honeybee hives. Comput. Electron. Agric. 2019, 156, 138-144. [CrossRef] 